
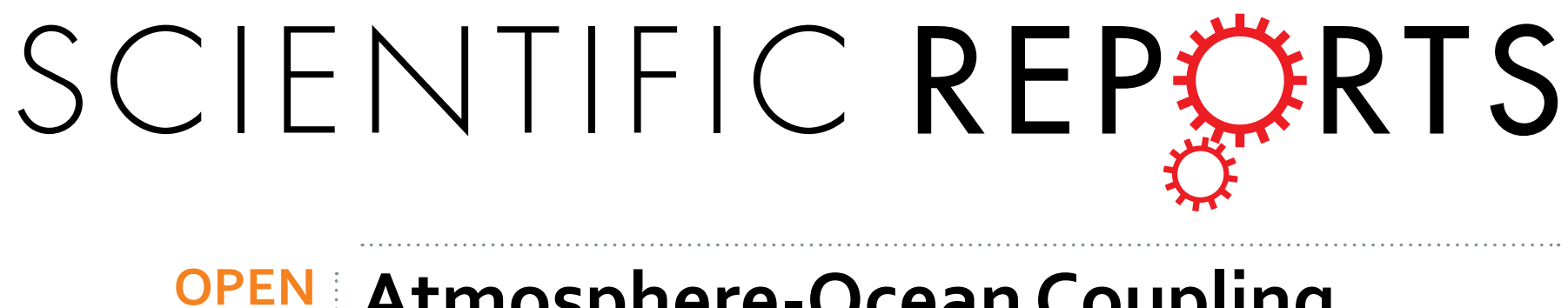

\title{
Atmosphere-Ocean Coupling
} Effect on Intense Tropical Cyclone Distribution and its Future Change

Received: 01 March 2016

Accepted: 21 June 2016

Published: 15 July 2016

\section{with $60 \mathrm{~km}-\mathrm{AOGCM}$}

\author{
Tomomichi Ogata ${ }^{1}$, Ryo Mizuta ${ }^{2}$, Yukimasa Adachi ${ }^{2,3}$, Hiroyuki Murakami ${ }^{4}$ \& Tomoaki Ose ${ }^{2}$
}

Atmosphere-ocean coupling effect on the frequency distribution of tropical cyclones (TCs) and its future change is studied using an atmosphere and ocean coupled general circulation model (AOGCM). In the present climate simulation, the atmosphere-ocean coupling in the AOGCM improves biases in the AGCM such as the poleward shift of the maximum of intense TC distribution in the Northern Hemisphere and too many intense TCs in the Southern Hemisphere. Particularly, subsurface cold water plays a key role to reduce these AGCM biases of intense TC distribution. Besides, the future change of intense TC distribution is significantly different between AOGCM and AGCM despite the same monthly SST. In the north Atlantic, subsurface warming causes larger increase in frequency of intense TCs in AOGCM than that in AGCM. Such subsurface warming in AOGCM also acts to alter large decrease of intense TC in AGCM to no significant change in AOGCM over the southwestern Indian Ocean. These results suggest that atmosphere-ocean coupling characterized by subsurface oceanic structure is responsible for more realistic intense TC distribution in the current climate simulation and gives significant impacts on its future projection.

Previous studies have suggested that the frequency of extreme events, such as heavy precipitation over East Asia $^{1}$, intense extratropical cyclones ${ }^{2}$, and heat waves ${ }^{3}$, will increase in the future. Tropical cyclones (TCs) are an important category of such extreme events, as they can cause substantial impacts on populated areas, in the form of strong winds and precipitation. Over East Asia and North America, in particular, TCs commonly lead to social and economic disasters where they make landfall. There is, therefore, considerable need for accurate regional projections of future TC activity ${ }^{4-7}$. Recent studies have found agreement in projections of a global reduction in TC number and an increase in mean TC intensity ${ }^{8-13}$ caused by a slowdown of the tropical circulation ${ }^{14,15}$. However, projected changes in individual basins remain uncertain ${ }^{10,16,17}$. Since the 1990 s, advances in computational resources have made high-resolution general circulation model (GCM) simulations possible. For example, the intensities of TCs simulated by the $20 \mathrm{~km}$ resolution atmosphere-only general circulation model (AGCM; MRI-AGCM3.2S) were much more realistic than results from the previous version of the model (MRI-AGCM3.1S) ${ }^{18}$. Using these models, a previous study ${ }^{19}$ found that TC frequency in the future climate decreased in both models over the Northwest Pacific (NWP), while projected frequency changes over the North Atlantic (NATL) were different between MRI-AGCM3.1S and MRI-AGCM3.2S, making the true situation unclear. However, in the present climate simulation in MRI-AGCM3.2S, a northward bias remains in the spatial distribution of the most extreme TCs (those with a maximum wind speed of more than $70 \mathrm{~ms}^{-1}$, known as Category 5 or C5) compared with observations ${ }^{18}$.

Previous studies have investigated the possible causes of such biases in intense TC distribution. Some have noted the importance of rapid and large TC-induced SST cooling that occurs through changes in the ocean subsurface ${ }^{20-22}$, although this explanation is not relevant to AGCM simulations using prescribed SST. In the Northern Hemisphere $(\mathrm{NH})$, the underlying subtropical mode water $\left(\mathrm{STMW}^{23-25}\right.$ ) raises the thermocline at around $20-30^{\circ} \mathrm{N}$, making the oceanic mixed layer shallower than at $10-20^{\circ} \mathrm{N}$. This shallow mixed layer north of

${ }^{1}$ Faculty of Life and Environmental Sciences, University of Tsukuba, Japan. ${ }^{2}$ Meteorological Research Institute, Tsukuba, Japan. ${ }^{3}$ Japan Meteorological Agency, Tokyo, Japan. ${ }^{4}$ Geophysical Fluid Dynamics Laboratory, Princeton, USA. Correspondence and requests for materials should be addressed to T. Ogata (email: ogata.tomomichi.ga@u. tsukuba.ac.jp) 

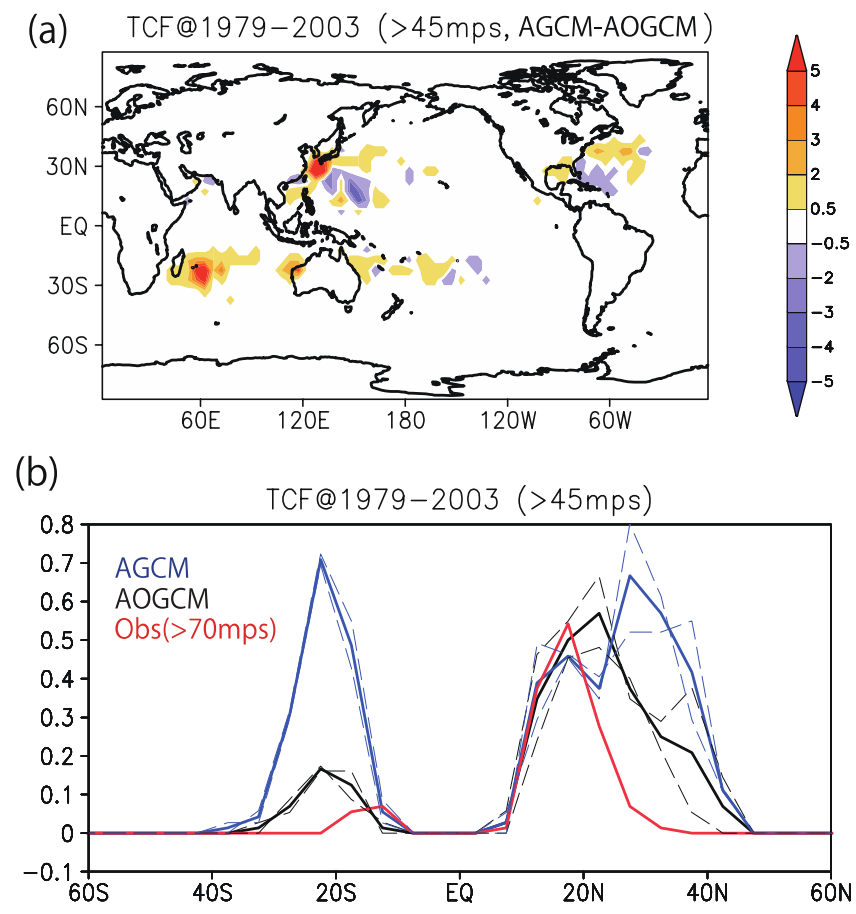

Figure 1. Air-sea coupling effect on the present-day intense TC frequency. (a) Difference in the intense TC (maximum wind speed $>45 \mathrm{~ms}^{-1}$ ) frequency between the AGCM and AOGCM simulations, in $5^{\circ} \times 5^{\circ}$ bins for 1979-2003 (units of $\left.(25 \mathrm{yr})^{-1}\right)$. (b) Zonal average intense TCF (in $5^{\circ} \times 5^{\circ}$ bins; units of $\left.(25 \mathrm{yr})^{-1}\right)$. The AOGCM (AGCM) results are shown in black (blue). Dashed lines show subsamples of the full period (1979-1990 and 1991-2003). Observed extreme (C5: maximum wind speed $>70 \mathrm{~ms}^{-1}$ ) TCF is shown in red. All plots and maps are generated by GrADS version 2.0.2 (http://cola.gmu.edu/grads/).

$20^{\circ} \mathrm{N}$ may suppress TC intensification through SST cooling. To test whether such an atmosphere-ocean coupling process can reduce the northward bias seen in the TC distribution in AGCMs using prescribed SST, coupling with an oceanic GCM (OGCM) is needed. A previous study ${ }^{26}$ investigated the importance of atmosphere-ocean coupling in assessing the distribution of intense TCs over the NWP using a $60 \mathrm{~km}$ resolution coupled atmosphere-ocean general circulation model (AOGCM). In this work, we extend the approach to study the effect of atmosphere-ocean coupling on intense TCs in other ocean basins, and their projected future changes.

\section{Results}

First, we measure the atmosphere-ocean coupling effect by comparing the TC climatology between AGCM and AOGCM simulations. Figure 1a shows the intense TC frequency (TCF) difference between the two simulations, in $5^{\circ} \times 5^{\circ}$ bins during $1979-2003$ [see a previous study ${ }^{18}$ for details of the TC tracking method]. The $60 \mathrm{~km}$ resolution of the AGCM is too coarse to realistically capture the frequency of C4 or C5 extreme TCs as seen in a $20 \mathrm{~km}$ $\mathrm{AGCM}^{18}$. Therefore, we choose TCs stronger than C3 (maximum wind speed $>45 \mathrm{~ms}^{-1}$ ) as 'intense' for this study. Although the $60 \mathrm{~km}$ AGCM has a quantitative bias in the TC intensity distribution due to its coarse resolution, the $20 \mathrm{~km}$ and $60 \mathrm{~km}$ AGCMs share common features in their northward bias in the TC intensity peak ${ }^{19}$.

The present study focuses on whether atmosphere-ocean coupling in the $60 \mathrm{~km}$ AOGCM can reduce the northward bias qualitatively compared with the $60 \mathrm{~km}$ AGCM. A positive TCF difference (Fig. 1a) around $20-30^{\circ} \mathrm{N}$ shows that the AGCM tends to simulate intense TCs more frequently than does the AOGCM, and that the northward bias can be seen not only in the NWP ${ }^{26}$ but also in the NATL and the Southern Hemisphere (SH). This result indicates that the simulation of intense TCF is affected by the atmosphere-ocean coupling present in the AOGCM.

Figure $1 \mathrm{~b}$ shows the meridional distribution of zonally averaged intense TCF during 1979-2003. In the AOGCM (black lines), the intense TCF peak is located around $15-25^{\circ} \mathrm{N}$, while the AGCM (blue lines) has a $\mathrm{NH}$ peak around $30^{\circ} \mathrm{N}$. In the $\mathrm{SH}$, an intense TCF peak around $25^{\circ} \mathrm{S}$ is greatly reduced in the AOGCM. Similar TCF distributions in different periods (1979-1990 and 1991-2003) suggest that the increase in intense TCF in the AGCM is robust around $25-35^{\circ} \mathrm{N}$ and $15-30^{\circ} \mathrm{S}$. Area averages for individual basins are listed in Table 1 . In the NWP and the NATL, a robust decrease in the AOGCM compared with the AGCM is found around $25-40^{\circ} \mathrm{N}$ ( $45 \%$ of AGCM in the NWP, and $48 \%$ of AGCM in the NATL). Decrease in AOGCM (11\% of AGCM) in the southwestern Indian Ocean (SWIO) is also robust.

For comparison, observed intense TCF (using only C5 TCs; i.e., those with maximum wind speed of more than $70 \mathrm{~ms}^{-1}$ ) during 1979-2003 is also shown in Fig. 1b. The peak in observed intense TCF is found around $10-20^{\circ} \mathrm{N}$, and TCF declines rapidly north of $20^{\circ} \mathrm{N}$. Comparison between the observed and AOGCM intense TCFs indicates that observed intense TCs induce greater SST cooling (cold-wake) via stronger TC-induced mixing, 


\begin{tabular}{|l|c|c|}
\hline & $\mathbf{6 0} \mathbf{~ k m ~ A O G C M ~}$ & 60 km AGCM \\
\hline SWIO $\left(40-80^{\circ} \mathrm{E}, 15-30^{\circ} \mathrm{S}\right)$ & $\mathbf{0 . 2 1 3}$ & $\mathbf{1 . 8 7 6}$ \\
\hline NWPs $\left(120-160^{\circ} \mathrm{E}, 10-25^{\circ} \mathrm{N}\right)$ & 3.537 & 2.918 \\
\hline NWPn $\left(120-160^{\circ} \mathrm{E}, 25-40^{\circ} \mathrm{N}\right)$ & $\mathbf{0 . 7 8 0}$ & $\mathbf{1 . 7 0 5}$ \\
\hline ATLs $\left(40-70^{\circ} \mathrm{W}, 10-25^{\circ} \mathrm{N}\right)$ & 0.219 & 0.053 \\
\hline ATLn $\left(40-70^{\circ} \mathrm{W}, 25-40^{\circ} \mathrm{N}\right)$ & $\mathbf{0 . 8 9 2}$ & $\mathbf{1 . 8 4 2}$ \\
\hline
\end{tabular}

Table 1. Area averages of intense TC frequency (maximum wind speed $>45 \mathrm{~ms}^{-1}$ ) in individual basins during 1979-2003 (units of (25 yr) $\left.{ }^{-1}\right)$. Bold characters indicate that the differences between the AOGCM and the AGCM have the same sign for comparisons during 1979-1990 and 1991-2003.

(a)

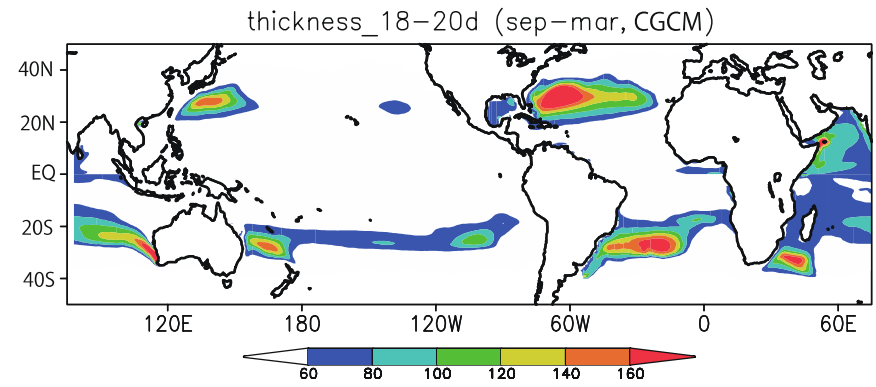

(b)

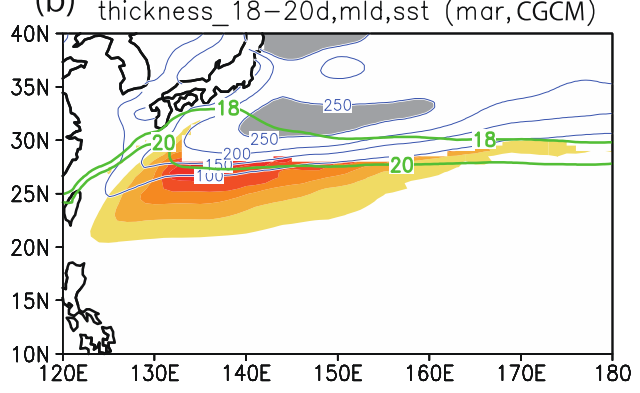

(c) thickness_18-20d,mld,sst (mar, CGCM)

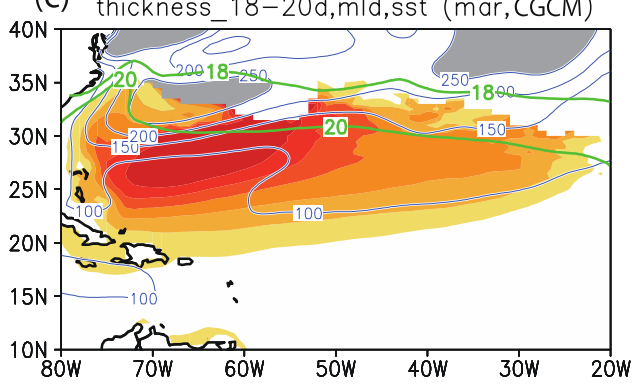

(d)

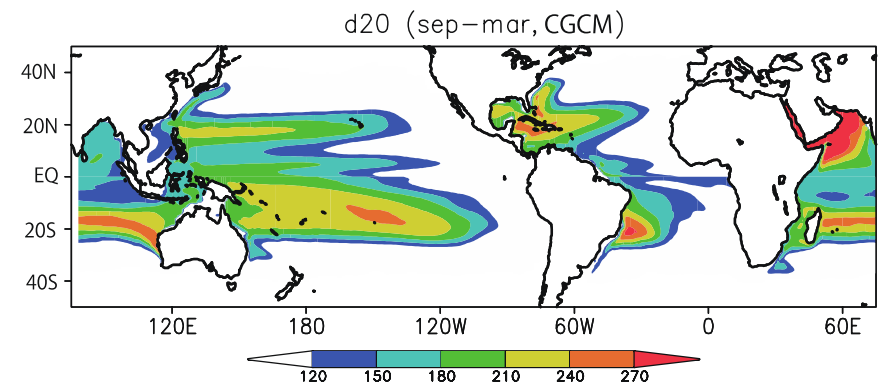

Figure 2. Subsurface ocean state in the AOGCM. (a) Horizontal distribution of AOGCM-simulated STMW (defined as $18-20^{\circ} \mathrm{C}$ water thickness, units of $\mathrm{m}$ ) in late summer (September in the $\mathrm{NH}$, March in the $\mathrm{SH}$ ). (b) Same as (a), but for late winter (March) in the NWP and (c) in the NATL. (d) Same as (a), but for the $20^{\circ} \mathrm{C}$ isotherm depth in late summer. In (b,c), MLD (SST) is shown by blue (green) contours, and MLDs of greater than $250 \mathrm{~m}$ are shaded in grey. All plots and maps are generated by GrADS version 2.0.2 (http://cola.gmu.edu/grads/).

resulting in a more rapidly decreasing TCF distribution with increasing latitude. In the $\mathrm{SH}$, the observed intense TCF is much smaller than in the NH. In contrast to the AGCM, the AOGCM captures this north-south asymmetry in the TCF. Overall, the intense TCF in the AOGCM exhibits more realistic features (e.g., the shift in the $\mathrm{NH}$ peak and the north-south asymmetry) than does that in the AGCM. These results indicate that atmosphereocean coupling is crucial for realistic simulations of intense TC distribution.

We now examine the behaviour of the subsurface ocean in the AOGCM. Figure 2a shows the subsurface $18-20^{\circ} \mathrm{C}$ water thickness, as a measure of the STMW, in late summer in each hemisphere. In the $\mathrm{NH}$, thick STMW is present around $20-35^{\circ} \mathrm{N}$, which raises the thermocline (Fig. $2 \mathrm{~b}, \mathrm{c}$ ). The STMW is formed during winter and spring (Fig. 2b,c). Thick, uniform mode water can form along the mixed layer depth (MLD) front, and the SST at the MLD front determines the properties of the STMW. In summer, the shallow seasonal thermocline 
(a)

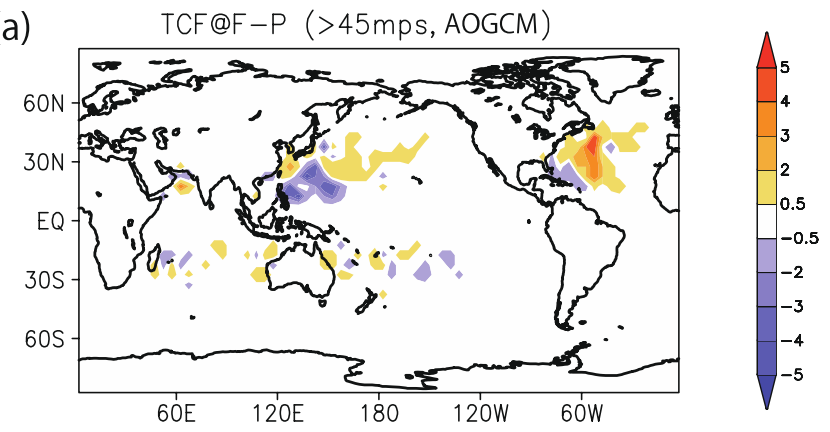

(b)

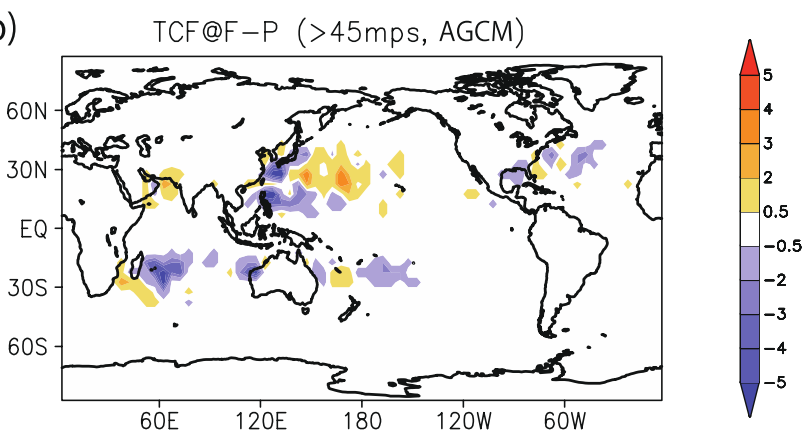

(c)

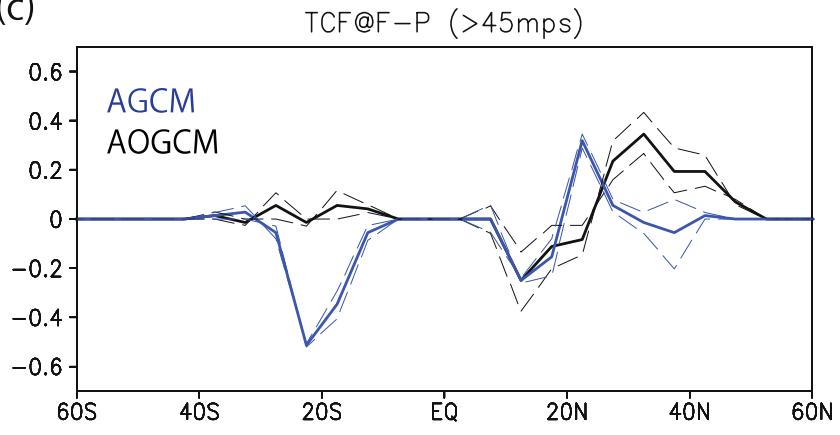

Figure 3. Differences in future changes in intense TC frequency between the AOGCM and the AGCM.

(a) Change in intense TCF between current and future climate simulations, in $5^{\circ} \times 5^{\circ}$ bins, in the AOGCM (units of $\left.(25 \mathrm{yr})^{-1}\right)$. (b) Same as (a), but for the AGCM. (c) Zonal average of intense TCF (in $5^{\circ} \times 5^{\circ}$ bins; units of $\left.(25 \mathrm{yr})^{-1}\right)$, for the AOGCM (black) and the AGCM (blue). Dashed lines show subsamples of the full period (2075-2086 minus 1979-1990, and 2087-2099 minus 1991-2003). All plots and maps are generated by GrADS version 2.0.2 (http://cola.gmu.edu/grads/).

produced via surface heat flux prevents the subduction of the STMW, but thick and uniform $18-20^{\circ} \mathrm{C}$ water remains (Fig. 2a). On the other hand, in the $\mathrm{SH}$ the contribution of thick $18-20^{\circ} \mathrm{C}$ water appears to be relatively weak. In the SWIO, the $18-20^{\circ} \mathrm{C}$ water thickness maximum cannot be clearly seen (Fig. 2a). Instead, a shallow $20^{\circ} \mathrm{C}$ isotherm appears around $5-15^{\circ} \mathrm{S}$ over the SWIO (Fig. $2 \mathrm{~d}$ ). Such shallow isotherm is a result of Ekman pumping and oceanic Rossby waves ${ }^{27,28}$, and may contribute to the less intense TCF in the SH.

Next, the effect of atmosphere-ocean coupling on the future climatology of intense TCs is investigated by comparing AGCM and AOGCM future climate simulations. A difference in the projected change in intense TCF can be seen over the NATL and the SWIO (Fig. 3a,b). In the NATL, the AOGCM shows a clear increase in intense TCF in the future, while such an increase is unclear in the AGCM. In the SWIO, the AGCM shows a clear decrease in intense TCF in the future, while such a decrease is unclear in the AOGCM. In terms of the zonal average (Fig. 3c), both AGCM and AOGCM show a small decrease in intense TCF around $15^{\circ} \mathrm{N}$, and that AGCM shows an increase in TCF around $20^{\circ} \mathrm{N}$ while AOGCM shows an increase around $30-40^{\circ} \mathrm{N}$. In the SH, the AGCM shows a large decrease in the future around $25^{\circ} \mathrm{S}$, while the AOGCM shows a weak increase. Differences between the models in terms of projected changes in intense TCF are not sensitive to different subsample periods (Fig. 3c), indicating that the differences around $20-50^{\circ} \mathrm{N}$ and $10-30^{\circ} \mathrm{S}$ are robust.

Area averages in individual basins are provided in Table 2. An increase in the NATL in the AOGCM (178\%) and a decrease in the SWIO in the AGCM (62\%) are robust, while changes in the NWP are not robust, due to large internal variability. According to observational analysis ${ }^{29}$ during 1970-2004, the number of the Category 4-5 TCs increases almost all over the basins. However, a recent observational study ${ }^{30}$ showed that the trends of the number of the Category 4-5 TCs during a more reliable period of 1990-2014 are insignificant all over the basins 


\begin{tabular}{|l|c|c|}
\hline & $\mathbf{6 0} \mathbf{~ k m ~ A O G C M}$ & $\mathbf{6 0} \mathbf{~ k m ~ A G C M}$ \\
\hline SWIO $\left(40-80^{\circ} \mathrm{E}, 15-35^{\circ} \mathrm{S}\right)$ & -0.004 & $-\mathbf{1 . 2 3 3}$ \\
\hline NWPs $\left(120-150^{\circ} \mathrm{E}, 10-25^{\circ} \mathrm{N}\right)$ & -1.950 & -1.695 \\
\hline NWPn $\left(150-180^{\circ} \mathrm{E}, 20-35^{\circ} \mathrm{N}\right)$ & 0.952 & 1.459 \\
\hline ATL $\left(30-70^{\circ} \mathrm{W}, 15-45^{\circ} \mathrm{N}\right)$ & $\mathbf{1 . 0 5 3}$ & -0.234 \\
\hline
\end{tabular}

Table 2. Area averages of intense TC frequency (maximum wind speed $>45 \mathrm{~m} / \mathrm{s}$ ) change (future minus present) (units of $\left.(25 \mathbf{~ y r})^{-1}\right)$. Bold characters indicate changes that satisfy two conditions: (1) the change is of the same sign for differences between 1979-1990 and 2075-2086, and between 1991-2003 and 2087-2099, and (2) the changes in the AOGCM and the AGCM are significantly different.

including the global average. Small SST warming of about $0.5^{\circ} \mathrm{C}$ in observation $\left(3^{\circ} \mathrm{C}\right.$ in our study) may explain the difference between the observational analysis and the future projections here ${ }^{9}$.

In addition to SST warming, the AOGCM shows a subsurface ocean warming, but the meridional structure differs between the surface and subsurface (Fig. 4). Previous studies have shown that vertically averaged ocean temperature is a good measure of mixing by intense $\mathrm{TCs}^{20,21}$. In this study, temperature averaged over the upper $100 \mathrm{~m}$ (Tav100) is used to represent the upper portion of the ocean that interacts with TCs and defines ocean heat content available for TC intensification. Tav100 is especially modified by the ocean response to TCs by mixing and upwelling ${ }^{20,21}$. In the NATL, SST is fairly uniform in the present climate simulation and exceeds $27^{\circ} \mathrm{C}$ almost everywhere, but Tav 100 exceeds $27^{\circ} \mathrm{C}$ around $10-20^{\circ} \mathrm{N}$ only. These cold subsurface conditions (also seen in Fig. 2) in the NATL contribute to the lower intense TCF in the AOGCM compared with the AGCM (Fig. 1). In the future climate simulation, the region in which Tav 100 exceeds $27^{\circ} \mathrm{C}$ extends to $30^{\circ} \mathrm{N}$ (Fig. $4 \mathrm{c}, \mathrm{d}$ ). Compared with the other basins, the deeper future subsurface warming weakens the subsurface impact on intense TCs, meaning that intense TCF change in the AOGCM is greater than that in the AGCM (Fig. 3). In the SWIO, Tav100 does not exceed $27^{\circ} \mathrm{C}$ anywhere in the present climate (Fig. 4e,f). The cold subsurface (also seen in Fig. 2) contributes to the decrease in TCF in the AOGCM compared with the AGCM (Fig. 1). In the future climate, a region in which Tav 100 exceeds $27^{\circ} \mathrm{C}$ appears north of $25^{\circ} \mathrm{S}$. This subsurface warming in the SWIO weakens the subsurface impact on intense TCs, leading to a weak increase in TCF in the AOGCM, whereas a large decrease is simulated by the AGCM (Fig. 3). In the NWP, a cold area (Tav100 below $27^{\circ} \mathrm{C}$ ) remains around $25-30^{\circ} \mathrm{N}$ in the future climate (Fig. 4a,b). Furthermore, compared with the NATL, subsurface warming is shallower in the NWP $\left(2.5^{\circ} \mathrm{C}\right.$ warming extends to $200 \mathrm{~m}$ depth in the NATL, but only to $150 \mathrm{~m}$ in the NWP). This shallow subsurface warming in the NWP may be responsible for the relatively small difference in TCF change between the AOGCM and the AGCM. It should be noted that the surface and subsurface warming are robust over the two subsampled periods (Supplementary Figure S1). A map of climatology and projected future changes in SST and temperature averaged over the upper $100 \mathrm{~m}$ and $200 \mathrm{~m}$ (Supplementary Figure S2) shows that deep warming reaching to $200 \mathrm{~m}$ (about $2.5-3^{\circ} \mathrm{C}$ in magnitude) can be seen around $20-30^{\circ} \mathrm{N}$. In the NATL, compared with the NWP, there is a larger meridional separation between the $24^{\circ} \mathrm{C}$ (equal to about $27^{\circ} \mathrm{C}$ in the future climate) and $27^{\circ} \mathrm{C}$ contours. Thus, subsurface thermodynamic conditions favourable to TC development (temperature above $27^{\circ} \mathrm{C}$ ) extend farther northward in the NATL than in the NWP. Overall, differences in the projected future changes in TCF can be attributed to the biases in the present-day simulations ${ }^{31}$ and to the future changes in subsurface thermodynamic conditions. This result highlights the fact that the ability to accurately simulate the present-day intense TCF is also important for the projection of future changes in intense TCF.

\section{Summary and Discussion}

The effect of atmosphere-ocean coupling on the frequency distribution of intense TCs and their future change has been studied using atmosphere-only (AGCM) and coupled (AOGCM) model experiments. The AOGCM displays smaller biases in TC distribution than does the AGCM, due to regionally varying atmosphere-ocean coupling. In the $\mathrm{NH}$ the peak in the distribution of intense TCs shifts equatorward in the AOGCM compared with the AGCM. The frequency of intense TCs in the SH decreases in the AOGCM, which better captures the observed north-south asymmetry in intense TC frequency. A reduction on the poleward flank of the intense TC meridional distribution is attributed to a cold subsurface ocean.

Projected future changes in the TC distribution are different in the AOGCM and the AGCM, despite the models having the same monthly mean SST in both the present and future climates. In the NATL, subsurface warming (exceeding $26-27^{\circ} \mathrm{C}$ ) in the AOGCM causes a large increase in intense TCs. Subsurface warming also acts to alter the projected change in the SWIO from a large decrease in intense TCs in the AGCM to an insignificant change in the AOGCM. These results suggest that atmosphere-ocean coupling, characterized by the subsurface ocean structure, leads to significant qualitative differences in the projected changes in intense TCs between the AGCM and the AOGCM.

We focused on the effect of atmosphere-ocean coupling on intense TCs only. Considering all TCs, the spatial pattern of changes in TCF is similar in both the AOGCM and the AGCM (Supplementary Figure S3), and is consistent with previous studies ${ }^{18,19}$. For example, an overall decrease in TCF is found in the SH in both models although a decrease in the AOGCM is insignificant in the SWIO, and significant TCF decreases in the NWP (west of around $160^{\circ} \mathrm{E}$ ) and the eastern Pacific (east of around $120^{\circ} \mathrm{W}$ ), and an increase in the central Pacific ${ }^{32}$ (around $120-180^{\circ} \mathrm{W}$ ) are common features between the AOGCM and the AGCM. On the other hand, the TCF is decreased in the western North Atlantic by a similar amount in both models, but in the eastern north Atlantic it is increased in the AOGCM and decreased in the AGCM. It should be noted that the spatial pattern of TCF change 
(a)

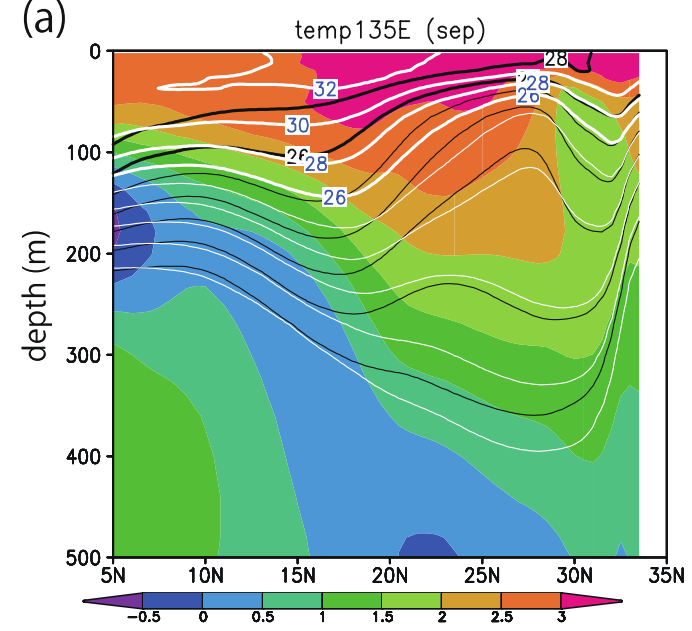

(b)
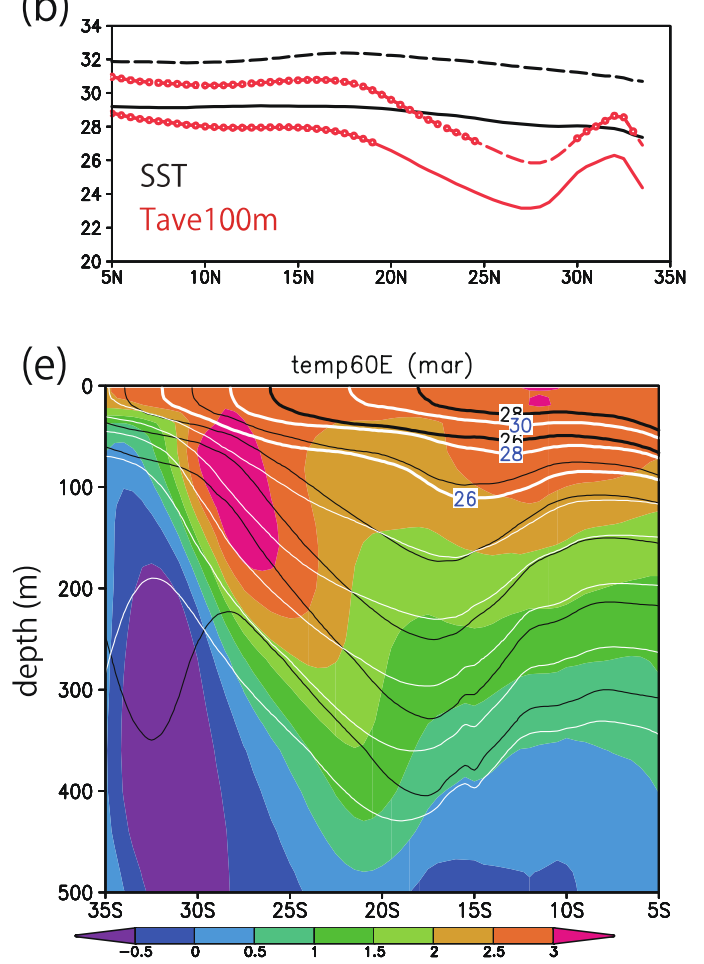

(f)

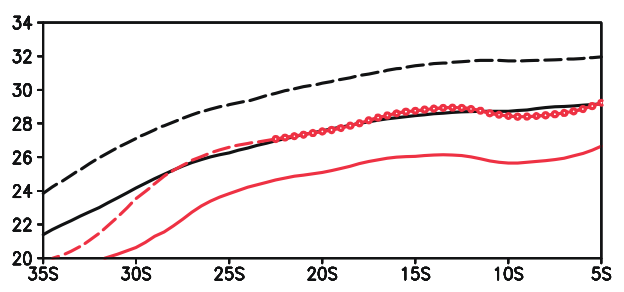

(e) $\quad$ temp60E (mar)

(f) (c)

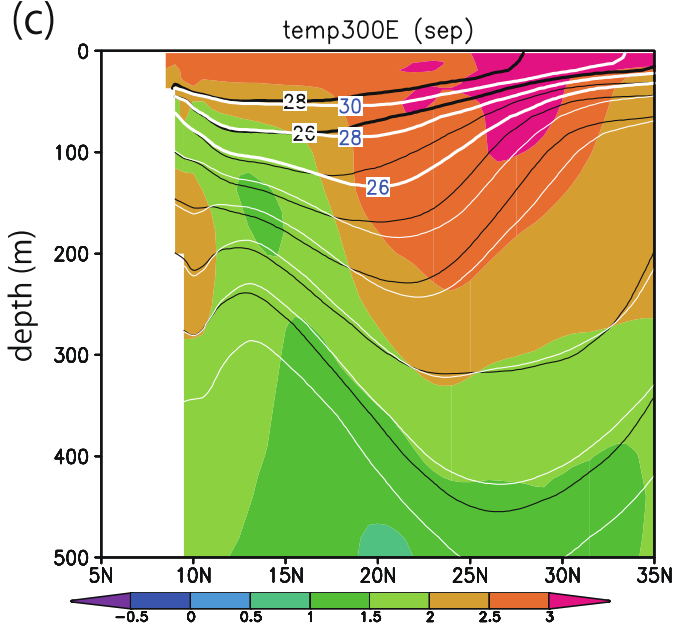

(d)

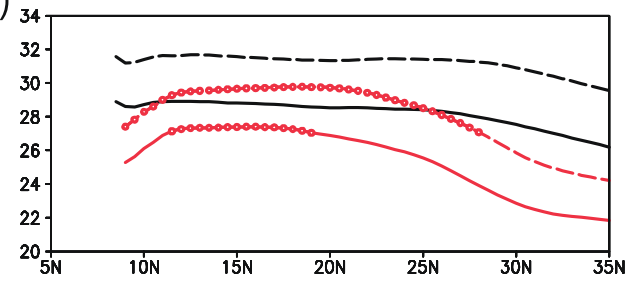

Figure 4. Future changes in the subsurface ocean. (a) Latitude-depth cross-sections of ocean temperature in the present (black contours) and future (white contours) climates, and the change (shading), and (b) meridional distributions of SST (black, in ${ }^{\circ} \mathrm{C}$ ) and Tav100 (red, in ${ }^{\circ} \mathrm{C}$ ) in the present (solid lines) and future (dashed lines) climates in September at $135^{\circ} \mathrm{E}$. (c,d) Same as (a,b), but for $60^{\circ} \mathrm{W}$ in September. (e,f) Same as (a,b), but for $60^{\circ} \mathrm{E}$ in March. Open circles in (b,d,f) mark areas with temperature above $27^{\circ} \mathrm{C}$. All plots and maps are generated by GrADS version 2.0.2 (http://cola.gmu.edu/grads/).

in the NATL in the AOGCM is similar to that found in previous studies ${ }^{33,34}$. In the eastern Atlantic, the climatological $20^{\circ} \mathrm{C}$ isotherm is relatively shallow, indicating that strong atmosphere-ocean coupling may be active in this region (not shown). A series of MRI-AGCM3.2 experiments ${ }^{9}$ (Supplementary Figure S4) also shows TCF 
decreases over the $\mathrm{SH}$ and in the NWP, and an increase in the central Pacific, which are robust with respect to the choice of future emissions scenario (CMIP3-A1B or CMIP5-RCP8.5), prescribed SST pattern ${ }^{35}$, and convection scheme. These features are also consistent with previous studies ${ }^{8-13}$. Other existing literature ${ }^{14,15}$ suggests that a slowdown of tropical circulation due to increase of vertical dry stability by the global warming can explain global TC decrease generally. For this reason, it is natural to consider that intense TCF also decreases in the SH and NWP under the global warming as well as weak TCF, though vertical wind shear is also important for regional uncertainty such as NATL ${ }^{10,16,17}$. On the other hand, TC intensity and intense/extreme TCF changes may include different aspects from case of all-TCF. In the former case, increase of TC intensity by local SST or subsurface ocean warming ${ }^{36}$ also becomes important. Our results of future experiments on air-sea coupling effects seem to support this aspect.

To obtain more realistic extreme TC distribution, recent studies suggest that an AOGCM with resolution of $20 \mathrm{~km}$ or finer is needed ${ }^{37}$. Our study has clarified the atmosphere-ocean coupling effect in a $60 \mathrm{~km}$ resolution AOGCM, but other recent studies indicate that further experiments with finer-resolution (e.g., $20 \mathrm{~km}$ ) AOGCMs are needed to measure the sensitivity of the effect to resolution. As a next step, a $20 \mathrm{~km}$ resolution AOGCM experiment, producing more realistic TC intensity distribution, is necessary to more accurately measure the atmosphere-ocean coupling effect. Furthermore, a high-resolution ocean, with resolution of $20 \mathrm{~km}$ or finer, is needed to adequately model mid-latitude SST fronts and narrow coastal currents ${ }^{38-40}$. A high-resolution ocean may also be important to more adequately simulate TC life-cycles ${ }^{41,42}$. Finally, TC activity may also have an impact on mean subsurface thermal structure and meridional heat transport ${ }^{43,44}$. Investigation of the role of TCs in controlling climate should be continued in order to improve climate modelling.

\section{Data and Models}

The AOGCM used in this study consists of an atmospheric global model of MRI-AGCM3.2 $\mathrm{H}^{45}$, with a $60 \mathrm{~km}$ horizontal resolution and 64 vertical levels (TL319L64), and an oceanic model of MRI.COM3 ${ }^{46}$, with a tripolar grid with $1^{\circ}$ zonal and $0.5^{\circ}$ meridional resolution, and 50 vertical levels. To adequately resolve the upper ocean structure, 10 levels (15 levels) are located in the upper $100 \mathrm{~m}(200 \mathrm{~m})$. The model is the same as that used in a previous study ${ }^{26}$.

Flux adjustment is often used in coupled GCMs to ensure realistic model simulations ${ }^{47}$. To simulate sub-seasonal atmosphere-ocean interaction while reproducing observed SST variability on the seasonal-to-interannual timescale in the present climate, monthly mean flux adjustment was performed in the AOGCM. This flux adjustment process was described in a previous study ${ }^{26}$. Here we refer to a simulation using the MRI-AGCM3.2H atmospheric model with prescribed SST from the AOGCM as the 'AGCM' simulation, while the atmosphere-ocean coupled simulation is referred to as the 'AOGCM' simulation. Each model was integrated from January 1979 to December 2003 to produce 'present' climate simulations ${ }^{26}$. Similarly, 'future' climate simulations were performed from January 2075 to December 2099 by adding future changes of boundary conditions (e.g., SST and sea ice) taken as the ensemble mean output of 28 CMIP5 models run under the RCP8.5 scenario $^{35}$ to their present (1979-2003) observed values.

\section{References}

1. Kusunoki, S. \& R. Mizuta. Change in the precipitation intensity over East Asia for the 20th and 21st centuries simulated by a global atmospheric models with 60-km grid size, J. Geophys. Res. 118, 11,007-11,016, doi: 10.1002/jgrd.50877 (2013).

2. Mizuta, R., M. Matsueda, H. Endo \& S. Yukimoto. Future change in extratropical cyclones associated with change in the upper troposphere. J. Climate, 24, 6456-6470 (2011)

3. Nakano, M., M. Matsueda \& M. Sugi. Future projections of heat waves around Japan simulated by CMIP3 and high-resolution Meteorological Research Institute atmospheric climate models. J. Geophys. Res. 118, doi: 10.1002/jgrd.50260 (2013).

4. Yokoi, S. \& Y. N. Takayabu. Multi-model projection of global warming impact on tropical cyclone genesis frequency over the western North Pacific. J. Meteor. Soc. Japan, 87, 525-538 (2009).

5. Knutson, T. R. et al. Tropical cyclones and climate change. Nat. Geosci. 3, 157-163 (2010).

6. Murakami, H., B. Wang \& A. Kitoh. Future change of western North Pacific typhoons: Projections by a 20-km-mesh global atmospheric model. J. Climate, 24, 1154-1169 (2011).

7. Colbert, A. J., B. J. Soden \& B. P. Kirtman. The Impact of Natural and Anthropogenic Climate Change on Western North Pacific Tropical Cyclone Tracks. J. Climate, 28, 1806-1823 (2015).

8. Zhao, M., I. M. Held, S. J. Lin \& G. A. Vecchi. Simulations of global hurricane climatology, interannual variability, and response to global warming using a 50-km resolution GCM. J. Climate, 22, 6653-6678 (2009).

9. Bell, R., J. Strachan, P. L. Vidale, K. Hodges \& M. Roberts. Response of tropical cyclones to idealized climate change experiments in a global high-resolution coupled general circulation model. J. Climate, 26, 7966-7980 (2013).

10. Tory, K. J., S. S. Chand, J. L. McBride, H. Ye \& R. A. Dare. Projected changes in late-twenty-first-century tropical cyclone frequency in 13 coupled climate models from phase 5 of the Coupled Model Intercomparison Project. J. Climate, 26, 9946-9959 (2013).

11. Gualdi, S., E. Scoccimarro \& A. Navarra. Changes in Tropical Cyclone Activity due to Global Warming: Results from a HighResolution Coupled General Circulation Model. J. Climate, 21, 5204 (2008).

12. Rathmann, N. M., S. Yang \& E. Kaas. Tropical cyclones in enhanced resolution CMIP5 experiments. Climate Dyn., 42, 665-681 (2014).

13. Kim, H. S. et al. Tropical cyclone simulation and response to $\mathrm{CO}_{2}$ doubling in the GFDL CM2.5 high-resolution coupled climate model. J. Climate, 27, 8034-8054 (2014).

14. Sugi, M., H. Murakami \& J. Yoshimura. On the mechanism of tropical cyclone frequency changes due to global warming. J. Meteor. Soc. Japan, 90, 397-408 (2012).

15. Vecchi, G. A. \& B. J. Soden. Global warming and the weakening of the tropical circulation. J. Climate, 20, 4316-4340 (2007).

16. Walsh, K. J. E., K. C. Nguyen \& J. L. McGregor. Fine-resolution regional climate model simulations of the impact of climate change on tropical cyclones near Australia. Climate Dyn. 22, 47-56 (2004).

17. Chauvin, F., J. F. Royer \& M. Déqué. Response of hurricane-type vortices to global warming as simulated by ARPEGE-Climat at high resolution. Climate Dyn. 27, 377-399 (2006).

18. Murakami, H. et al. Future changes in tropical cyclone activity projected by the new high-resolution MRI-AGCM. J. Climate, 25, 3237-3260 (2012).

19. Murakami, H., R. Mizuta \& E. Shindo. Future changes in tropical cyclone activity projected by multi-physics and multi-SST ensemble experiments using the 60-km-mesh MRI-AGCM. Climate Dyn. 39, 2569-2584 (2012). 
20. Price, J. F. Metrics of hurricane-ocean interaction: vertically-integrated or vertically-averaged ocean temperature? Ocean Science, 5, 351-368 (2009).

21. Vincent, E. M. et al. Assessing the oceanic control on the amplitude of sea surface cooling induced by tropical cyclones, J. Geophys. Res. 117, C05023 (2012a)

22. Lloyd, I. D. \& G. A. Vecchi. Observational evidence for oceanic controls on hurricane intensity. J. Climate, 24, 1138-1153 (2011).

23. Worthington, L. V. The 18 Degree Water in the Sargasso Sea. Deep-Sea Res. 5, 297-305 (1959).

24. Joyce, T. M., C. Deser \& M. A. Spall The relation between decadal variability of subtropical mode water and the North Atlantic Oscillation. J. Climate, 13, 2550-2569 (2000).

25. Oka, E. \& B. Qiu. Progress of North Pacific mode water research in the past decade. J. Oceanogr. 68, 5-20 (2012).

26. Ogata, T., R. Mizuta, Y. Adachi, H. Murakami \& T. Ose. Effect of air-sea coupling on the frequency distribution of intense tropical cyclones over the Northwestern Pacific. Geophys. Res. Lett. 42, doi: 10.1002/2015GL066774 (2015).

27. Masumoto, Y. \& G. Meyers. Forced Rossby waves in the southern tropical Indian Ocean. J. Geophys. Res. 103, 27589-27602 (1998).

28. Yokoi, T., T. Tozuka \& T. Yamagata. Seasonal variation of the Seychelles Dome. J. Climate, 21, 3740-3754 (2008).

29. Webster, P. J., G. J. Holland, J. A. Curry \& H. R. Chang. Changes in tropical cyclone number, duration, and intensity in a warming environment. Science, 309, 1844-1846 (2005).

30. Klotzbach, P. J. \& C. W. Landsea. Extremely intense hurricanes: revisiting Webster et al. (2005) after 10 years. J. Climate, 28, 7621-7629 (2015).

31. Murakami, H., P.-C. Hsu, O. Arakawa \& T. Li. Influence of model biases on projected future changes in tropical cyclone frequency of occurrence. J. Climate, 27, 2159-2181 (2014).

32. Murakami, H., B. Wang, T. Li \& A. Kitoh. Projected increase in tropical cyclones near Hawaii. Nat. Climate Change, 3, 749-754 (2013).

33. Murakami, H. \& B. Wang. Future change of North Atlantic tropical cyclone tracks: Projection by a 20-km-mesh global climate model. J. Climate, 23, 2699-2721 (2010).

34. Colbert, A. J., B. J. Soden, G. A. Vecchi \& B. P. Kirtman. The impact of anthropogenic climate change on North Atlantic tropical cyclone tracks. J. Climate, 26, 4088-4095 (2013).

35. Mizuta, R. et al. Classification of CMIP5 future climate responses by the tropical sea surface temperature changes. SOLA, 10, 167-171, doi: 10.2151/sola.2014-03 (2014)

36. Emanuel, K. A. The dependence of hurricane intensity on climate. Nature, 326, 483-485 (1987).

37. Murakami, H. et al. Simulation and prediction of Category 4 and 5 hurricanes in the high-resolution GFDL HiFLOR coupled climate model. J. Climate, doi: 10.1175/JCLI-D-15-0216.1 (2015).

38. Masumoto, Y. et al. A fifty-year eddy-resolving simulation of the world ocean-Preliminary outcomes of OFES (OGCM for the Earth Simulator). J. Earth Simulat. 1, 35-56 (2004).

39. Hayasaki, M., R. Kawamura, M. Mori \& M. Watanabe. Response of extratropical cyclone activity to the Kuroshio large meander in northern winter. Geophys. Res. Lett. 40, 2851-2855, doi: 10.1002/grl.50546 (2013).

40. Ogata, T. \& A. Kitoh. Effect of High-Resolution SST on 60km-AGCM Simulated Snowfall in Japan. SOLA, 10, 131-135, doi: 10.2151/ sola.2014-027 (2014).

41. Vincent, E. M. et al. Processes setting the characteristics of sea surface cooling induced by tropical cyclones. J. Geophys. Res. 117, C02020 (2012).

42. Jullien, S. et al. Ocean feedback to tropical cyclones: climatology and processes. Climate Dyn. 43(9-10), 2831-2854 (2014).

43. Jullien, S. et al. Impact of tropical cyclones on the heat budget of the South Pacific Ocean. J. Phys. Oceanogr. 42, 1882-1906 (2012).

44. Scoccimarro, E. et al. Effects of tropical cyclones on ocean heat transport in a high-resolution coupled general circulation model. J. Climate, 24, 4368-4384 (2011).

45. Mizuta, R. et al. Climate simulations using the improved MRI-AGCM with 20-km grid. J. Meteor. Soc. Japan, 90A, 233-258 (2012).

46. Tsujino, H. et al. Reference manual for the Meteorological Research Institute Community Ocean Model (MRI.COM) Version 3. Tech. Rep. of MRI, 59, 241 pp. (2010).

47. Yukimoto, S. et al. Present-day climate and climate sensitivity in the Meteorological Research Institute coupled GCM Version 2.3 (MRI-CGCM2.3). J. Meteor. Soc. Japan. 84, 333-363 (2006).

\section{Acknowledgements}

All figures were produced using GrADS version 2.0.2 (http://cola.gmu.edu/grads/). This work was conducted under the SOUSEI Program of the Ministry of Education, Culture, Sports, Science, and Technology (MEXT) of Japan.

\section{Author Contributions}

T. Ogata designed and organized the research as the corresponding author. R.M., Y.A., H.M. and T. Ose provided comments throughout the research. R.M. and Y.A. developed the AOGCM and numerical experiments were executed on the Earth Simulator by R.M. and T. Ogata.

\section{Additional Information}

Supplementary information accompanies this paper at http://www.nature.com/srep

Competing financial interests: The authors declare no competing financial interests.

How to cite this article: Ogata, T. et al. Atmosphere-Ocean Coupling Effect on Intense Tropical Cyclone Distribution and its Future Change with 60 km-AOGCM. Sci. Rep. 6, 29800; doi: 10.1038/srep29800 (2016).

(c) (i) This work is licensed under a Creative Commons Attribution 4.0 International License. The images or other third party material in this article are included in the article's Creative Commons license, unless indicated otherwise in the credit line; if the material is not included under the Creative Commons license, users will need to obtain permission from the license holder to reproduce the material. To view a copy of this license, visit http://creativecommons.org/licenses/by/4.0/ 